\title{
The Historical Evolution and Analysis of the Fiscal Policy of China's Cultural Industry
}

\author{
Peng Liu 1,2, Yunfeng Zhang2 \\ ${ }^{1}$ The College of Economics and Management, The Southwest Jiaotong University, Chengdu, China \\ ${ }^{2}$ The College of Economics and Management, The Shandong University of Science and Technology, Qingdao, \\ China \\ Email:66995070@qq.com,2503060698@qq.com
}

Received 14 March 2016; accepted 18 April 2016; published 21 April 2016

Copyright (C) 2016 by authors and Scientific Research Publishing Inc.

This work is licensed under the Creative Commons Attribution International License (CC BY). http://creativecommons.org/licenses/by/4.0/

(c) (i) Open Access

\begin{abstract}
The practice of economic development in countries around the world shows that the financial policy of cultural industry plays a very important role in the development of cultural industry. Therefore, all governments pay great attention to the use of the financial policy tool of cultural industry. Through the analysis of fiscal policies of cultural industry made by the central government over the years, because of large-scale cultural expenditure with low efficiency, it can be concluded that the effect of fiscal policies is not good as we expect. Fiscal policies of cultural industry can keep better coordination on the whole, but there are still great policy deficiencies. The paper studies relevant fiscal policies of China's cultural industry and puts forward some useful recommendations.
\end{abstract}

\section{Keywords}

\section{Cultural Industry, Fiscal Policy, Cultural Expenditure}

\section{Introduction}

Since the reform and opening up, especially after the promulgation of the Report about Economic Policy Suggestions of Ministry of Culture on Cultural Industry in 1991, the fiscal subsidy policies that are aimed at promoting the development of cultural industry have played an important role in prospering the market for cultural products, enriching the cultural life and improving the quality of spiritual civilization. Up to now, there have been thousands of fiscal policies and specific measures of cultural industry in national and local level.

Now, scholars both at home and abroad made abundant achievements in the study of financial policy of cultural industry. Most of foreign researches focus on the study of the cultural industry in the market economy. Only a few scholars have paid attention to the fiscal policy of cultural industry. Based on the previous study of 
the relationship of culture, economy and policy, Kong L carried on a comprehensive study in 2000 which analyzed cultural and economic policies adopted by western countries from the 50's of the last century to the end [1]. Hesmondhalgh, from the current and historical perspective, conducted a systematic research of cultural industry in 2007. He took the western developed countries as an example, analyzed the great significance of financial policies in promoting the cultural industry's development, and concluded that policy and economy would have an impact on cultural industry [2]. Arnold found that the development of cultural industries can act on the real economy and society, and the government should take full account of its role in the development of cultural policies [3].

Due to the differences in economic system and financial system at home and abroad, the research of fiscal policy of domestic cultural industry is in the majority. Hu studied the influence of globalization on the policy choice of cultural industry [4]. Li analyzed the constraints in the development of local cultural industries, and put forward proper policy choices to promote the development of local cultural industry in terms of the transformation of financial functions, the adjustment of cultural investment mechanisms and so on [5]. Li argued that the traditional role of the government restricted the integrated development of cultural industry in Yangtze River Delta [6]. Wang et al. studied the fiscal policies from the financial support, the internal structure of fiscal allocation and financing channels of cultural industry, and then made some relevant reform proposals [7]. Guo and Li introduced preferential tax policies of cultural industry generally adopted in European and American countries from the aspects of cultural area, employees and cultural industry. And then he developed related policy recommendations to improve the preferential tax legal system of cultural industry [8]. Zhang and Fu found that, under the background of incomplete reform of cultural system, the administrative monopoly and regional division of cultural industry, the financial investment mechanism and cultural control and unmatched development model hindered the effective allocation of productive factors of cultural industry and resulted in a high cost for cultural enterprises to reap a political benefit [9]. Hu and $\mathrm{Wu}$ (2014) pointed out that there were some deficiencies in the fiscal policy of our cultural industry, mainly manifested as policy support which was not prominent and targeted, and inadequate awareness of the risk of financial subsidies [10]. Through the analysis of financial support mode on cultural industry in America, France, England, Japan and Korea, Yan and Yu put forward some targeted suggestions on the development of cultural industry in China [11].

In summary, many scholars at home and abroad have studied the financial subsidies of cultural industry from different aspects. However, these studies mainly focus on local fiscal policy of cultural industry, and the policy developed by the central government is less concerned. This paper is different from most previous studies but similar to only Wang's in research method, whereas the conclusion distinguishes. This paper, based on the introduction of fiscal policies of cultural industry implemented by central government, mainly studies the effect, financial support and coordination of fiscal policies since 2003 and puts forward recommendations for further improvement of fiscal policy and development of cultural industry.

\section{The Historical Evolution of Fiscal Policy of Cultural Industry}

\subsection{First Stage (1978-1990)}

In the early stage of reform and opening up, there is no real cultural industry in China. The production and supply of cultural products are basically dominated by the government's propaganda department and cultural management department. Since the late 80's of the last century, with the deepening of the economic reform, Ministry of culture and other government departments have issued a series of documents, such as the Opinions on the Reform of Artistic Performance Organization, the Notice on Improving the Management of Party, and the Interim Measures on Carrying out the paid service and business activity in Newspapers and Periodicals Press. The trend of industrialization and marketization began to appear in mass entertainment, advertisement and cultural manufacturing industry. In this stage, from the financial policy perspective, the government began to reduce the subsidies for cultural sector by stages and in branches. And the policy of "independent accounting, financial self-sufficiency, no tax evasion, no fiscal subsidies" conducted by government gave birth to the marketization and industrialization of advertising and issuing transactions in the field of newspaper, broadcast and television.

\subsection{Second Stage (1991-2002)}

In this stage, cultural industry has been fully developed. The government has gradually transferred management 
means from "direct management" to "indirect management", and promoted the development of cultural industry by formulating fiscal subsidy policy. The concept of cultural economy was firstly put forward in the Report about Economic Policy Suggestions of Ministry of Culture on Cultural Industry in 1991. Then the press business was included in the Tertiary Industry in 1993. Several cultural institutions including the TV station were reformed into enterprises in 1998. The concept of cultural industry was developed in the Suggestions of the Central Committee of the Communist Party on Formulating the 10th 5-year Plan in National Economy in 2000. With the development of cultural industry, the fiscal subsidies have changed. Some provisions of the State Council on further improving the cultural and economic policies and the Notice of Economic Policies on Supporting the Cultural Industry and other documents established the system of construction fee for cultural industry, tax incentives and special funds.

\subsection{Third Stage (2003-So Far)}

In 2003, the Decision about Consummating Socialist Market economy System developed on the third plenary session of the sixteenth CPC central committee mentioned that cultural industry was the pillar of economy, and it was necessary to improve related policies of cultural industry. Then the Outline of The State Eleventh FiveYear Plan for Construction of Culture and the Outline of The State Twelfth Five-Year Plan for Construction of Culture required the construction of public cultural service system, the improvement of the system of culture market and the development of cultural industry. In this stage, cultural industry achieved rapid development. In addition to continue to maintain the prior practice, central government made policies of subsidizing for import and export of cultural product and service, local cultural industry and private capital investment in cultural industry.

\section{The Development Status of Cultural Industry with the Support of Fiscal Policy}

\subsection{The Lower Proportion of Cultural Expenditure on the National Financial Expenditure}

According to the China Statistics Yearbook, the national financial expenditure of culture, sports and media is used to indicate the cultural industry funds. Due to the statistics caliber has changed and relevant data is difficult to obtain, the paper only analyzes the proportion of cultural expenditure on the national financial expenditure from 2007 to 2014.

From Figure 1, we can see that the proportion of cultural expenditure on the national financial expenditure has been fluctuating between $1.72 \%$ and $1.83 \%$. In 2009, the cultural industry funds accounted for $1.82 \%$ of the national fiscal expenditure, reaching the peak in recent years. However, this proportion fell to the lowest level, which accounted for $1.72 \%$ of the national fiscal expenditure. Then, cultural industry funds began to increase gradually, reaching $1.81 \%$ of the national fiscal expenditure in 2013. According to the Ministry of Finance, the cultural industry founds reached 269 billion and 100 yuan that was accounted for $1.77 \%$ of the national fiscal

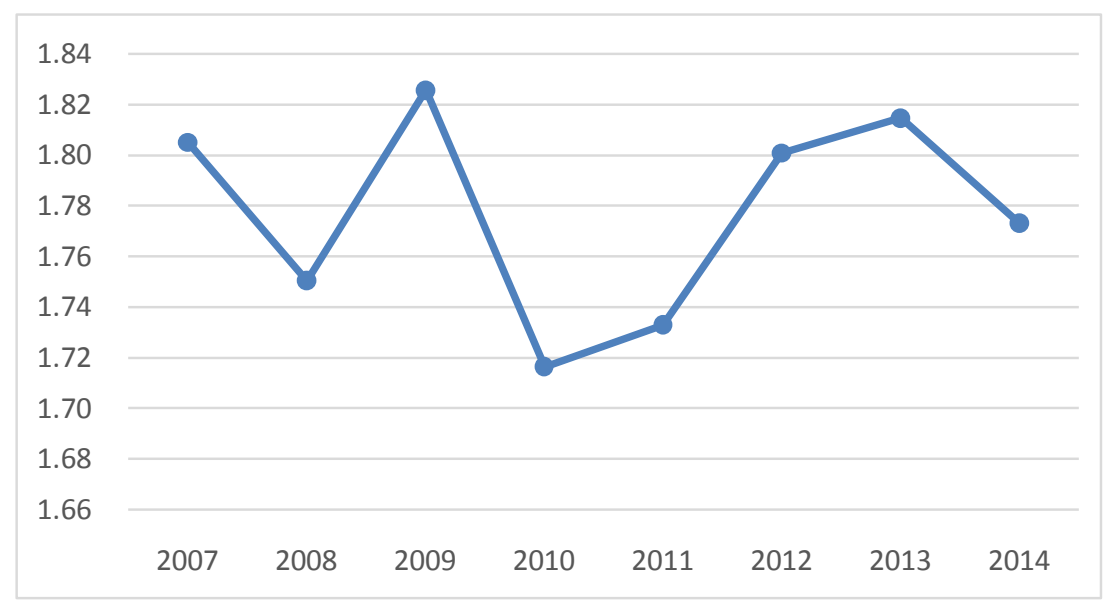

Figure 1. The proportion of cultural expenditure on the national financial expenditure from 2007 to 2014. 
expenditure, dropping 0.04 percentage points than that in 2013. The proportion of cultural expenditure on the national financial expenditure appears to decline in following years.

\subsection{The Slower Growth Rate of Cultural Industry Funds}

Since 2007, the average growth rate of cultural industry funds not only mostly below the growth rate of fiscal expenditure in the same period, but also behind the growth rate of other social undertakings funds, causing an increasing gap with other social undertakings.

Figure 2 reflects the national fiscal expenditures in science, education, culture and hygiene undertakings from 2007 to 2014. We can see that cultural industry funds not only is less than others in absolute numbers, also is obviously lagging behind in the growth rate.

\subsection{The Analysis on the Coordination of Fiscal Subsidy Policies}

The fiscal policies adopted by central government over the years can be divided into four aspects: development plans, tax incentives, grant funds and qualifications. Also the features shown in two aspects: on the one hand, these policies keep a good continuity which do not interrupt or contradict each other especially in terms of development plans and tax incentives. On the other hand, there has been a more complete system of fiscal policies of cultural industry, including special subsidies, investment funds, government acquisition, tax incentives, fiscal investment and financing and qualification examination. These policies also reflect the principle of the separation of powers between governments. Now, the central government is mainly responsible for working out strategic development plans, while local governments, especially at municipal and county level, are real performers of cultural industry policies who are in charge of the specific affairs.

It is should be noted that, up to now, there is no policy focusing on how to conduct performance evaluation of the fiscal subsidies and funds among existing fiscal policies. They all lay down the means and procedures of project application and main directions and scale of investment. In another word, cultural industry can achieve a development as long as it gets fiscal subsidies or funds. Because of not considering the efficiency in the use of capitals, the cultural resources can not realize rational allocation and effective usage.

\section{The Suggestions}

\subsection{To Reasonably Define the Scope of Fiscal Support for Cultural Industry, and Improve the Efficiency of Financial Funds}

The government should redefine the scope of financial support for cultural industries, and differ the effort of financial investment and subsidy between nonprofit cultural undertakings and operative cultural industry.

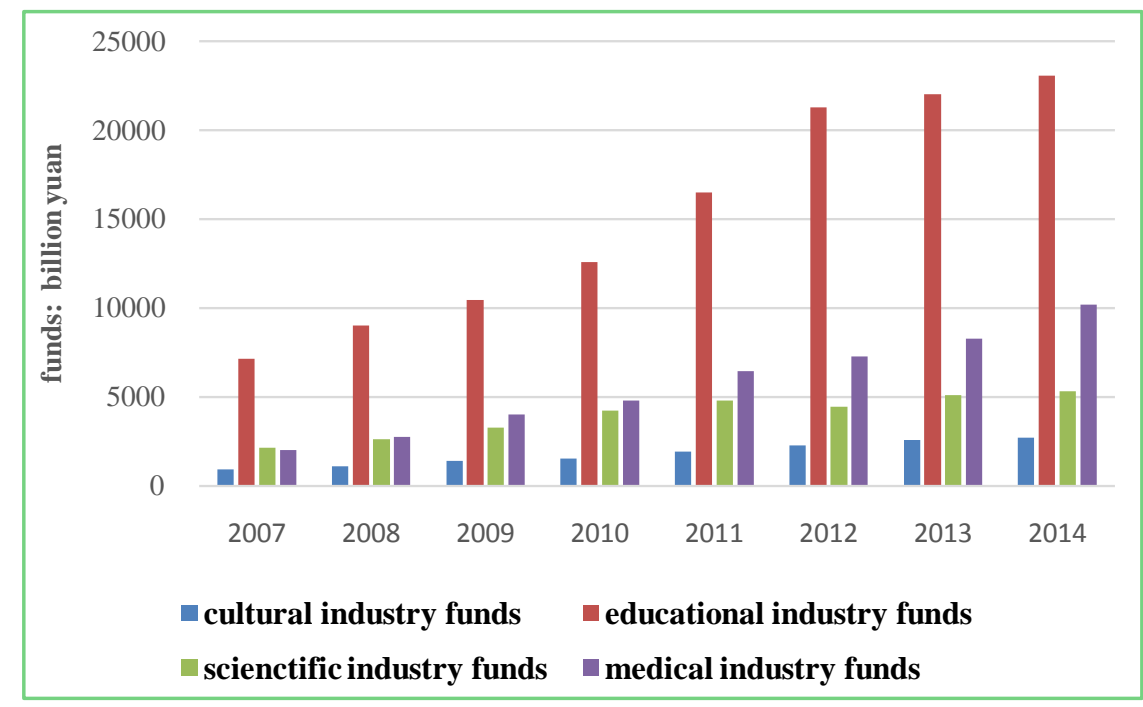

Figure 2. The comparison of expenditures on various social undertakings. 
Firstly, all governments should pay more attention to the development of nonprofit cultural undertakings to protect people's basic cultural right and interests. Governments should increase the proportion of cultural, sports and media expenditures for nonprofit cultural undertakings, thus effectively improving the cultural infrastructure construction and constantly improve the level of public cultural services. Moreover, it is necessary to improve the efficiency of the use of financial funds when governments invest more in the nonprofit cultural undertakings.

Secondly, the operative cultural industry can not only create economic benefits, but also bring social benefits. Therefore, governments should continue to effectively channel the financial funds to the creative cultural industry and emerging cultural industry. In order to crack down on the production and sales of cultural products which are pirated or contain the inappropriate contents such as superstition, pornography and violence, governments should establish efficient law enforcement and supervision agencies. Specially speaking, governments should increase the existing special funds; adjust the conditions, standers and directions of declaration of the fiscal subsidies; exert great efforts to protect the intellectual property; focus on fostering leading cultural enterprises and establish a modern system of cultural industry and so on.

Finally, governments should promote the establishment and improvement of the market mechanism of the management culture industry by means of financial means. On the one hand, it needs to actively explore the transformation and reform management of cultural institutions and state-owned enterprises, and to ensure that the value of state-owned assets is maintained and added. On the other hand, it needs to make more market subjects involved in the development of operative cultural industry by taking rational fiscal subsidy means, and to build powerful cultural brand and encourage enterprise group to survive in a competitive market.

\subsection{To Establish a Long-Term Mechanism of Financial Subsidies for the Operative Cultural Industry}

Now, the central government subsidize the cultural industry though the special funds for cultural industry and the special funds for the protection of national intangible cultural heritage and others. The special funds for the protection of national intangible cultural heritage later are mainly subsidized nonprofit cultural industry in terms of the public cultural service system, the protection of national intangible cultural heritage and the equipment purchase of multi-use cultural centers in towns. While the special funds for cultural industry are mainly established for the enterprises engaging in operative cultural industry, which aim at promoting the reform in the cultural system, cultivating a number of leading cultural enterprises and building a modern cultural industry system. In addition, there have been many special funds offered by provincial and municipal governments to promote the development of cultural industry in jurisdiction, such as the special funds for Beijing's cultural industry and the special funds for the development of Shenzhen's cultural industry. They have played a great important role to the rapid development of local cultural industry. Because these fiscal subsidies are mostly provided in form of project, there are problems of emphasizing on the management of project application instead of project tracking evaluation and assessment. As for various financial subsidies, this paper thinks that it is necessary to establish an examination system of the whole process of project including project application, approval, fund allocation, project tracking evaluation and assessment. In view of the particularity of the social benefits of cultural products, it requires to determine the reasonable evaluation criteria and indicators in order to make the performance appraisal of special funds more scientific and standardized. The author designs the whole project management process seen in Figure 3, trying to establish a long-term mechanism of financial subsidies to operative cultural industry which centers on establishing a reasonable system of performance appraisal of the project funds and improving the efficiency of the use of funds.

\subsection{To Promote the Innovation in Investing and Financing Mechanism of Cultural Industry}

As an important way to promote the further development and prosperity of China's cultural industry, a market-oriented investing and financing mechanism should be established. It can not only solve the problem of funds that the development of cultural industry requires, but also help cultural enterprises to exploit market channels, cultivate new business, and improve the business model. But there is a main problem in investing and financing mechanism of cultural industry, manifesting as relatively single market subjects and limited financing means. Although there are some useful attempts, such as Chinese Cultural Industry Investment Fund, Dachen Cultural Tourism Investment Fund, and Eastern Star Culture Communication Investment Fund, it is far away 


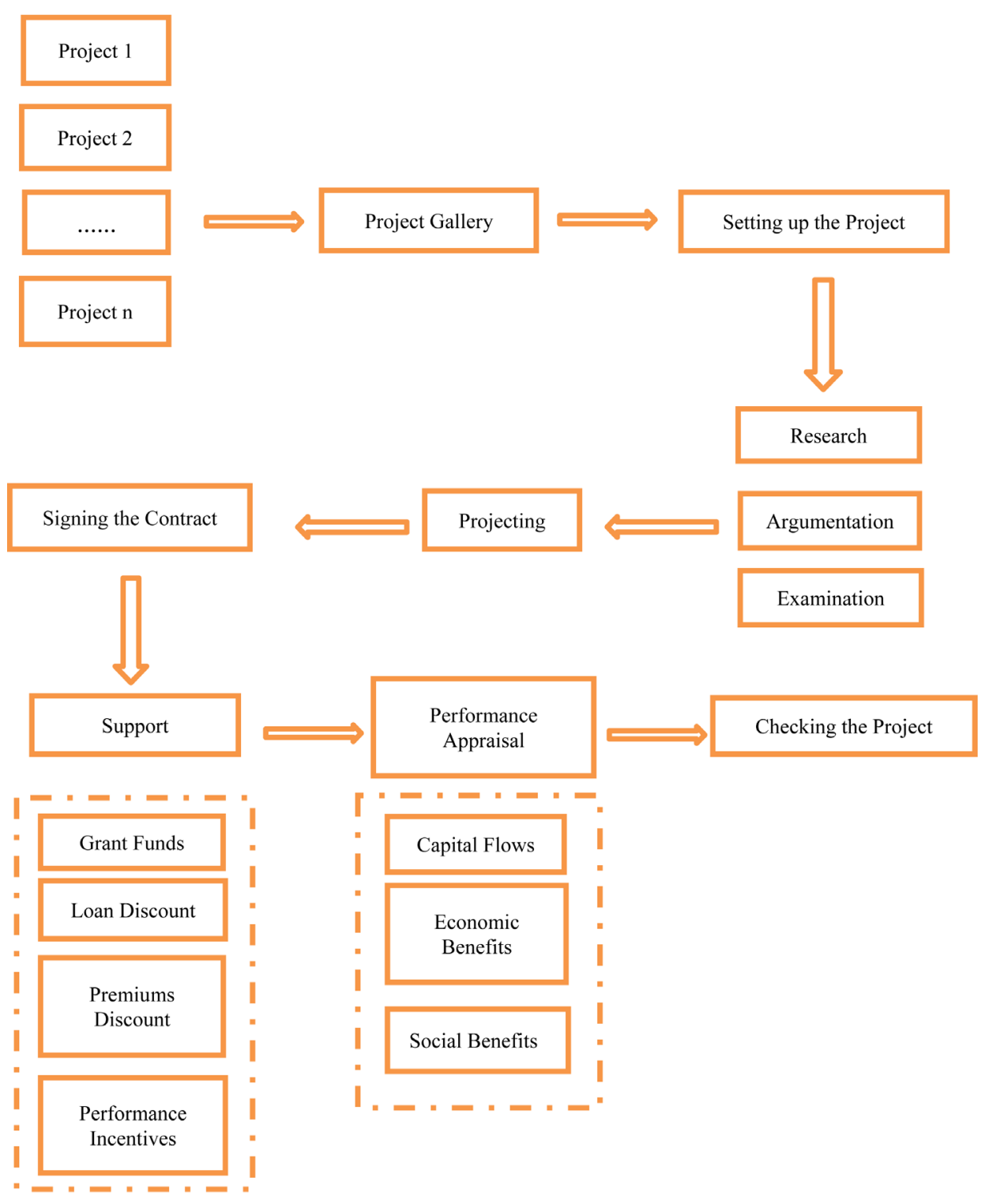

Figure 3. The whole project management process.

from the diversification of investment subjects and channels that the market-oriented investing and financing mechanism requires.

Today, the slow development and weak profitability can be clearly observed in China's cultural industry. The profit-driven capitals under the investing and financing mechanism of cultural industry determine that it is difficult to attract more private capitals if the investments in cultural industry fail to obtain enough returns. That is to say, only when the cultural industry achieves rapid development, can the investment value of the cultural industry be reflected and more capitals enter the cultural industry. In turn, it will simulate further development of cultural industry. Therefore, governments should make more preferential and guaranteed fiscal policies. Specifically, it needs to appropriately improve profitability of cultural industry investment funds to reduce operating costs; also to enable all cultural industry investment funds to equally enjoy investment opportunities and rights protection.

\section{Conclusion}

The introduction of fiscal policies of cultural industry adopted by central government over the years just focuses 
on the policies themselves, which does not consider the decision-making process. Through the above research, the paper draws following conclusions: from the perspective of the effect of fiscal policies, the growth of the value of cultural industry is not the same as the growth of expenditure on cultural expenditure. From the horizontal comparison of the extent of fiscal support, the results seem satisfied but with a lower overall expenditure efficiency. Finally, although cultural industry policies coordinate with each on the whole, there are still serious policy deficiencies; therefore, based on the analysis of development status of fiscal policy of cultural industry, the paper puts forward some relevant reform recommendations.

\section{Acknowledgements}

Authors would like to acknowledge the financial support from the Qingdao Philosophy and Social Science Planning Project "Study on the incentive mechanism of Qingdao's cultural industry fiscal subsidy” (QDSKL150452).

\section{References}

[1] Kong, L. (2000) Culture Economy, Policy: Trends and Developments. Geoforum, 4, 385-390. http://dx.doi.org/10.1016/S0016-7185(00)00004-X

[2] Hesmondhalgh, D. (2007) The Cultural Industries. Sage, Thousand Oaks, 174-175.

[3] Arnold, B. (2009) The European Union and the Culture Industries. Regulation and the Public Interest, 13, 74-89.

[4] Hu, H.L. (2004) The Thoughts on the Current Cultural Reform. Academic Monthly, 6, 60-65.

[5] Li, X.J. (2009) The Choice of Local Fiscal Policy to Promote the Development of Cultural Industry. Public Finance Research, 8, 76-78.

[6] Li, Y. (2010) The Orientation of Government Role in the Process of the Integration of Cultural Industry in the Yangtze River Delta. EconForum, 10, 91-93.

[7] Wang, D.G. (2011) Study on the Fiscal Policy of Promoting the Development of Chinese Cultural Industry. Study and Practice, 6, 105-111.

[8] Guo, Y.J. and Li, H.J. (2012) The Tax Preferential Legal System of Cultural Industry in Europe and America and Its Enlightenment to China. Journal of Wuhan University, 1, 75-79.

[9] Zhang, F.H. and Fu, C.W. (2013) The Effectiveness and Optimization Strategy of the Investment and Financing of China's Cultural Industry and Financial Policy. Learning and Practice, 8, 115-122.

[10] Hu, R.C. and Wu, J.Z. (2014) Support the Development of Cultural and Creative Industries in the Financial Policy Research. Economic Aspect, 1, 92-95.

[11] Yan, K. and Yu, S.Y. (2015) Support the Development of Cultural Industry Financial Policy Research. Journal of Huazhong Normal University, 3, 9-21. 